\title{
Lengua escrita \\ e inteligencia
}

\author{
María Soledad Mena Andrade
}

Una persona no es pobre porque es analfabeta; es analfabeta porque es pobre.

Paulo Freire

Considerar la escritura como un grado mayor de conocimiento y un puente para mejorarlo puede llevar a una confusión frente a la riqueza de la oralidad. A esto habría que sumarle una consideración fundamental sobre el aprendizaje como una «práctica situada». María Soledad Mena, profesora y coordinadora de la Maestría de Investigación en Educación de la Universidad Andina Simón Bolivar, Sede Ecuador, hace un recorrido sobre estas consideraciones para estimular nuevas visiones pedagógicas.

\section{6}

\section{El Homo sapiens} existe desde hace más de 250000 años y su primera escritura data de hace apenas 6000 .

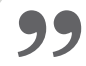

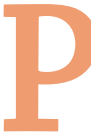

ara muchos investigadores, la lengua escrita significa una «evolución» de la humanidad, tal como ocurrió con la hominización de los primates al surgir el habla. En aquella ocasión, la posibilidad de comunicación provocó un desarrollo específico de la especie Homo sapiens, haciendo que la oralidad se convirtiera en un elemento esencial de la estructura humana. Podríamos decir que no hay culturas sin lengua, es parte constitutiva de los seres humanos, que nacemos con el cerebro dispuesto para hablar sin que nadie nos enseñe. Bastaría con estar inmersos en una sociedad para, a los cinco años, hablar perfectamente un idioma.

La lengua escrita no tiene esta característica biológica. Es artificial. Hemos interiorizado a la lectura y a la escritura de manera tan profunda que nos hemos olvidado de esta característica y hemos llegado a pensar que son competencias naturales. Nos resulta muy difícil concebir un mundo sin textos escritos. El Homo sapiens existe desde hace más de 250000 años y su primera escritura data de hace apenas 6000. Nacemos con un aparato fonador y auditivo que nos permite hablar y escuchar, ${ }^{1}$ pero no venimos al mundo con un

1 Si bien es cierto que la mayoría de los seres humanos biológicamente tenemos audición y hablamos, también hay personas sordas que establecen, de forma natural, mecanismos de comunicación no escrita. 


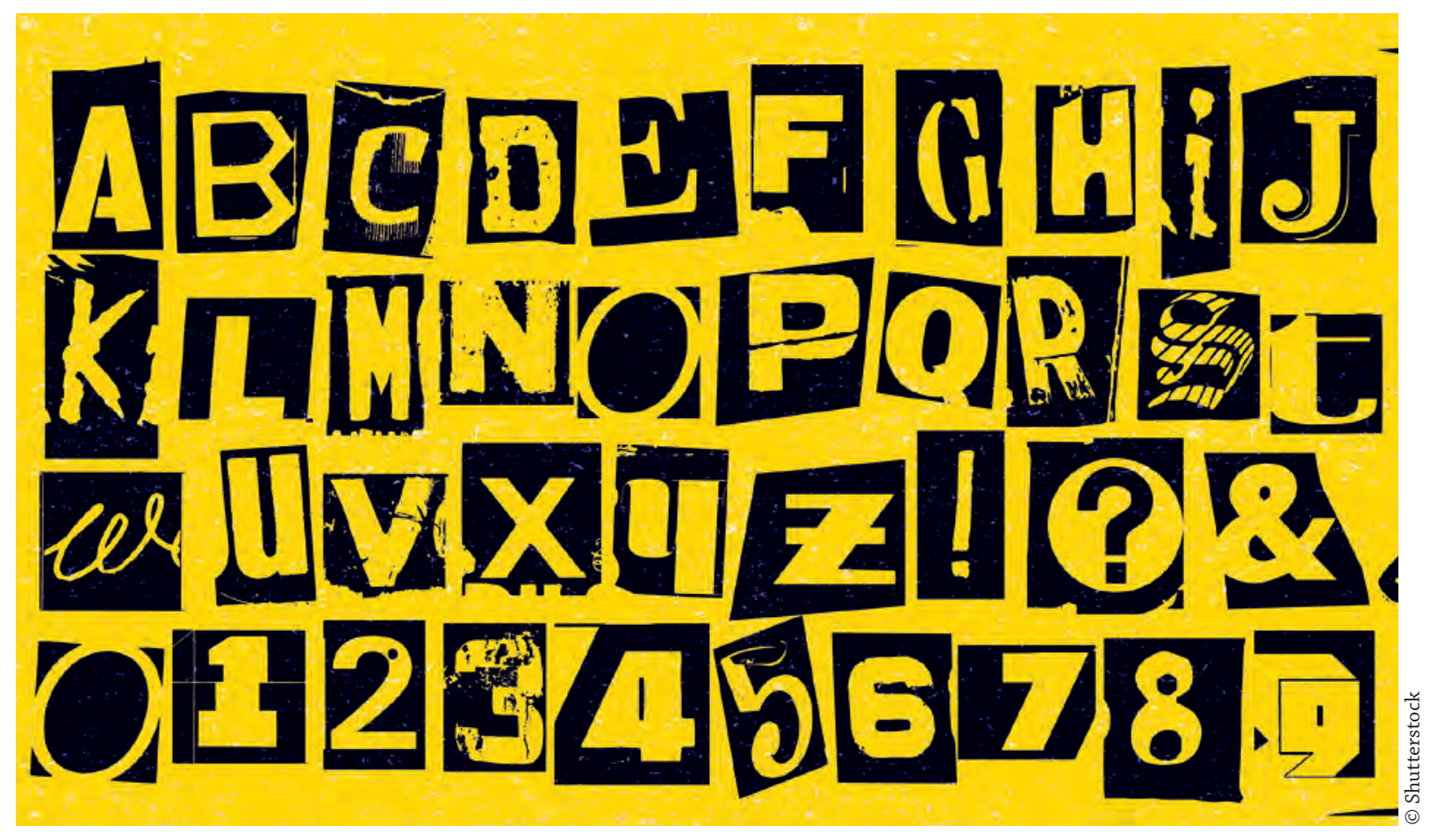

cerebro naturalmente programado para leer y escribir. Los humanos debemos aprender esta modalidad de lenguaje y alguien nos la tiene que enseñar.

En la década de los 60, ante la preocupación de averiguar la influencia de la escritura en la capacidad de pensar de las personas, autores como Eric Havelock, Walter Ong y David Olson, entre otros pensadores de la Escuela de Toronto, proclamaron la tesis que asegura que la aparición de la escritura significó una revolución cognitiva de la raza humana. Según este enfoque, el pensamiento en las culturas escritas es objetivo, es un razonamiento abstracto, descontextualizado (independiente de los sentidos), racional, lógico y capaz de realizar operaciones mentales complejas. Los autores relacionan a la escritura con las habilidades cognitivas y de pensamiento superior. Sostienen, además, que el mundo de la oralidad se caracteriza por la ausencia de todas estas cualidades. Carece de categorías analíticas complejas, son concretas, tradicionalistas, redundantes; la estructura de su pensamiento es aditivo, no subordinado y cargado de epítetos. En otras palabras, los no letrados poseen un pensamiento menos abstracto, viven impregnados en su contexto concreto y, en conclusión, tienen menos posibilidades de un pensamiento complejo y crítico.

A partir de esta corriente académica, la reflexión sobre la lengua escrita comienza a presentar una dicotomía entre la oralidad y la escritura, atribuyendo a esta última la capacidad de evolucionar la conciencia humana. Esta dicotomía se conoce como la Gran División, que no es otra cosa que la separación jerárquica entre las culturas oral y alfabética - entre la mente primitiva y el pensamiento racional-, confiriéndole a la escritura la cualidad de conducir la mente de los letrados a niveles superiores de inteligencia.

Desgraciadamente, este mito que considera a la escritura como la otra cara de la inteligencia, asociada íntimamente a la capacidad cognitiva de las personas, entró en el seno de la escuela. Al inscribir prácticas de lectura distanciadas del lenguaje de los estudiantes se envía el mensaje de que leer es comprender textos complejos, exógenos y sofisticados. Y al erigir una valoración superior de la lengua escrita sobre el discurso oral, se consolida el estatus elitista de la lengua escrita como el bien simbólico propio de la clase hegemónica, a la que solo unos pocos pueden acceder. 
Pienso que esta elitización de la lengua escrita se remonta a sus inicios, cuando apareció ligada a la contabilidad y como un mecanismo de control de la naciente ciudad-Estado de Sumeria. Las huellas en arcilla sirvieron para contabilizar la producción y el cobro de impuestos. Luego, para registrar las primeras leyes, el código de Hammurabi reguló la convivencia de las personas. Esas marcas también se usaron para describir las hazañas de los reyes y dioses; así se originó la leyenda de Gilgamesh. En otras palabras, la lengua escrita nació atrapada por el poder, mientras que el pueblo quedó totalmente marginado de esta modalidad de comunicación.

Esta acta de bautizo de la lengua escrita marca su identidad excluyente, que se refuerza en la escuela al convertirla en una «actividad» llena de reglas y normas impuestas, que condicionan su uso y terminan expulsando a muchos de sus potenciales usuarios. Otra manera de secuestrar la lengua escrita es pensarla como una técnica, un objeto estático alejado de su uso, de su contexto social y cultural. Bajo esta concepción, la lengua se norma en un estándar de lo escrito y las actividades escolares de lectura y escritura se reducen a un conjunto de ejercicios descontextualizados, que cobran forma principalmente para ejercitar la normatividad de la lengua y, en el mejor de los casos, para desarrollar las capacidades cognoscitivas de los estudiantes, pensándolas como prerrequisitos para la comprensión lectora y producción de textos.

La teoría de que la lengua escrita expresa un verdadero progreso en la comunidad humana está presente en la escuela, y fortalece la concepción "autónoma» ${ }^{2}$ de la lengua escrita. Es decir, al considerarla una herramienta cognitiva instrumental y prerrequisito para otros aprendizajes culturales, se induce a pensar que quien no sabe leer y escribir no sabe nada y no puede aprender. En otras palabras, se aprende a leer y a escribir, y luego se aplican estos conocimientos a otras disciplinas: la filosofía, la sociología, la historia, etc. Esta noción de destreza instrumental está muy presente no solo en la educación básica, sino también en la universidad. Los docentes separan el pensamiento disciplinar de su redacción o comprensión de textos. ${ }^{3}$ Esto también explica cómo se aborda su enseñanza en las aulas, en gran parte descrita en el párrafo anterior.

2 Brian Street caracteriza como modelo «autónomo» a la concepción de lengua escrita independiente de los contextos sociales y culturales de las personas. En este contexto, la lectura y la escritura son habilidades técnicas y neutrales.

3 Muchos docentes universitarios se quejan de que sus estudiantes «no saben leer ni escribir» pensando que esta es una «técnica» que debieron haber aprendido antes. Según Paula Carlino, la enseñanza de las asignaturas en la educación superior debe integrar la enseñanza de la lectura y escritura por las siguientes razones: a. la relación indisociable entre pensamiento y lenguaje; b. la enseñanza de la lectura y escritura depende del tratamiento de los contenidos disciplinares; c. los docentes deben hacerse cargo de la enseñanza de la lectura y escritura en cada asignatura. Ver Paula Carlino, "Alfabetización académica: Un cambio necesario, algunas alternativas posibles". Educere 6, n.o 20 (2003): 409-420. https://www.aacademica.org/paula.carlino/23
Otra manera de secuestrar la lengua escrita es pensarla como una técnica, un objeto estático alejado de su uso, de su contexto social y cultural. 
Otra manera en que la escuela interioriza y

nas, se arrebata a los docentes la posibilidad de difunde la concepción de que la lengua escrita se encuentra aliada con la inteligencia es cuando la piensa como «neutral», aun cuando sabemos que es una construcción social y que se inscribe en las estructuras de poder que conforman una cultura. En otras palabras, la lengua escrita no es neutral, sino que viene a representar el entorno social particular del que surgió. Los textos y las actividades de lectura y escritura en las instituciones escolares privilegian e imponen la realidad de un grupo social. Esto es lo que Bourdieu llama violencia simbólica. Para este autor, una de las principales causas de la desigualdad escolar reside en las diferencias entre la cultura de la escolarización y la de los diversos grupos de la sociedad. La escuela, al considerar que la lectura es de inteligentes, asevera que los estudiantes que tienen buenas notas en las asignaturas relacionadas con ella tienen capacidades cognitivas superiores. No se reconoce la familiaridad que estos alumnos tienen con los temas, el lenguaje y el contexto de esas lecturas, que es lo que posibilita su comprensión. Así, al desconocer el grado de familiaridad que los distintos estudiantes tienen con los textos (conocimientos previos), se considera que la comprensión lectora es el resultado de una capacidad cognitiva superior. Con esto se consigue la repetición del patrón de que solo unos pocos triunfan, perpetuándose la desigualdad en nombre de la igualdad.

Esta concepción de la lectura contradice la afirmación de que la lengua escrita es artificial y debe ser enseñada como un proceso comunicativo contextualizado. Al considerarla como una capacidad cognitiva, aparecería en el momento mismo de nacer, reforzándose el dicho popular: «Lo que natura no da, Salamanca no presta». Es decir, al identificar a la lengua escrita con las capacidades cognitivas de las perso-

\section{Al identificar a la lengua escrita con las capacidades cognitivas de las personas, se arrebata a los docentes la posibilidad de intervenir, y se les asigna la tarea de validar estos «dones», presentes solo en algunos estudiantes.}

la estructura cognitiva de las personas. Se realizaron indagaciones que identificaron que tales destrezas cognoscitivas, que se adjudicaban a la escritura, provenían de las experiencias de escolaridad de las personas. Por otro lado, ubicaron a muchas comunidades ágrafas con las características cognitivas que se atribuían solamente a la escritura. También encontraron formas de pensamiento en sociedades con escritura que desdecían sus virtudes. Estos resultados llevaron a que muchos de estos autores y seguidores del enfoque de la Gran División reconocieran las limitaciones de sus propuestas iniciales e incitaran a superar la jerarquía de la lengua escrita sobre la oral.

$\mathrm{Si}$ bien todos los resultados de estas nuevas investigaciones cuestionaron esa visión 
de elegir a los «capaces» y de excluir a una gran parte de la población escolar. Esta forma de selección es funcional a la reproducción de las inequidades del sistema porque encubre los privilegios de un extracto social dominante. Esta concepción monista de la lengua escrita es restringida, jerárquica y excluyente.

Según Virginia Zavala, investigadora peruana en temas referentes a la enseñanza de la lengua escrita, literacidad se define como la manera de usar dicha lengua en el marco de un propósito social y contexto específico: «Escribir ya no es solo un producto (lingüístico) o un proceso (cognitivo), sino una práctica situada, social, material, ideológica e histórica». En otras palabras, la lectura y la escritura no son fines en sí mismos. Las personas no leen ni escriben para leer y escribir. Nadie toma la guía telefónica solamente para leer, así como tampoco escribe un reclamo para ejercitar la caligrafía, o lee un anuncio clasificado porque sí. Se lee la guía telefónica para conseguir una dirección o un teléfono, se escribe un reclamo porque se desea expresar un descontento, y se lee un anuncio clasificado cuando se requiere un servicio o un bien. Esta realidad nos remite a que el uso de la lectura y escritura no se limita a aprender una mera técnica, sino que implica una complicidad con los valores, con las prácticas sociales y exige un conocimiento del contexto.

El enfoque de los NEL da un giro a la indagación sobre la lengua escrita. Mueve el eje de la reflexión ubicada en la perspectiva individual de habilidad cognitiva hacia la consideración de los aspectos contextuales, a plantear la lectura y escritura como prácticas sociales, históricas y culturales. Según Zavala, «la literacidad siempre implica una manera de usar la lectura y la escritura en el marco de un propósito social específico». Este enfoque de la lengua escrita no solo disuelve la dicotomía entre la lengua oral y escrita, diferenciándolas desde el uso que las personas hacen de ellas, sino que modifica radicalmente su enseñanza.

Desde las nuevas literacidades, la didáctica de la lengua escrita no justifica las afirmaciones sobre la naturaleza autónoma del conocimiento, del saber y de la lengua escrita de los contextos sociales, culturales y políticos de las personas. Es decir, no nos despojamos de nuestra cultura, nuestros valores y pensamientos para comprender o escribir un texto. ¡No! Lo hacemos desde allí. Cada hablante, escritor/lector, aporta con su forma de ver el mundo, sus prácticas de lenguaje, su historia y sus experiencias a la hora de leer y escribir. Según Lev Vygotsky, el conocimiento individual de una persona, sus valores, principios y formas de pensar se construyen en la interacción con su contexto sociocultural. La pluralidad del pensamiento es una característica humana que se deriva de la pluralidad de contextos en los que viven y desenvuelven las personas. Esta se expresa en las varias maneras de interpretar y de construir un texto, así

\section{6}

El uso de la lectura

y escritura no se

limita a aprender

una mera técnica,

sino que implica una

complicidad con

los valores, con las

prácticas sociales y

exige un conocimiento

del contexto. 
